\title{
Interferência de plantas daninhas no estabelecimento do trevo branco como cultura forrageira
}

\author{
Interference of weeds in the establishment of white clover as forage crop
}

\author{
Maurício Zanovello Schuster ${ }^{I^{*}}$ Leonardo Silvestri Szymczak $^{\mathrm{I}}$ Sebastião Brasil Campos Lustosa ${ }^{\mathrm{II}}$ \\ Adelino Pelissari ${ }^{I}$ Anibal de Moraes ${ }^{I}$ Reinaldo Francisco ${ }^{I I I}$
}

RESUMO

A interferência das plantas daninhas é um dos principais fatores que influencia no estabelecimento das pastagens e, dentro das pastagens, o trevo branco é uma importante Fabaceae utilizada na alimentação animal. O objetivo deste trabalho foi determinar os períodos de interferência das plantas daninhas sobre o trevo branco, o qual foi submetido a períodos de convivência e de controle do mato. Foram realizados levantamentos fitossociológicos em cada período de convivência da cultura com a comunidade infestante e aos 119 dias para os períodos de controle de convívio. Os dados de produção de matéria seca de trevo branco foram ajustados ao modelo de regressão não linear sigmoidal de Boltzmann, adotando-se um nível de redução da produtividade de $5 \%$. Os resultados revelaram que o período anterior à interferência (PAI) foi de 20 dias após a emergência (DAE), o período total, de prevenção à interferência, foi 82DAE e o período crítico, de prevenção à interferência, foi de 62 dias. As perdas de produtividade por matocompetição podem chegar a 96\%, sendo necessário o controle das plantas daninhas aos 20DAE, prolongando-se até aos 62DAE.

Palavras-chave: Trifolium repens L., competição, produtividade, PAI.

\section{ABSTRACT}

Interference of weeds is a major factor influencing the establishment of pastures and rangeland in the white clover is an important Fabaceae used in animal feed. The objective of this study was to determine the periods of weed interference on the white clover, which was subjected to periods living and weed control. Phytosociological surveys were conducted in each period of coexistence of culture with weeds and 119 days for the control periods of conviviality. Data on dry matter production of white clover were adjusted to model nonlinear regression sigmoidal Boltzmann, adopting a tolerance level of yield reduction of 5\%.
The results revealed that the period before interference was 20 days after emergence (DAE), the total period of interference prevention was $82 \mathrm{DAE}$ and the critical period of interference prevention were 62 days. Productivity losses by weed competition can reach $96 \%$, requiring weed control at 20DAE, extending up to 62DAE.

Key words: Trifolium repens L., competition, productivity, PBI.

\section{INTRODUÇÃO}

Segundo o relatório da ANUALPEC (2011), de cada 7,5kg de carne bovina do mundo, $1 \mathrm{~kg}$ é produzido no Brasil, onde os sistemas de produção pecuária, em sua maioria, são oriundos de pastagens. Para tanto, é fundamental, na formação das pastagens, a utilização de forrageiras com boa qualidade nutricional para um adequado desempenho animal.

O trevo branco (Trifolium repens L.) é uma fabácea que se destaca, entre as forrageiras, pela qualidade da forragem produzida e, entre os trevos, por possuir a maior capacidade de fixação de nitrogênio (ASSMANN et al., 2007). Contudo, entre as maiores limitações da utilização de fabáceas forrageiras sob pastejo, estão o lento estabelecimento e baixa persistência, conforme observado por BARCELLOS et al. (2008).

O estabelecimento das espécies forrageiras é considerado por LUSTOSA et al. (2011) como fator fundamental para uma boa produção de forragem e a

'Departamento de Fitotecnia e Fitossanitarismo, Universidade Federal do Paraná (UFPR), Rua dos Funcionários, 1540, 80035-050 Curitiba, PR, Brasil. E-mail: mauricioschus@gmail.com. *Autor para correspondência.

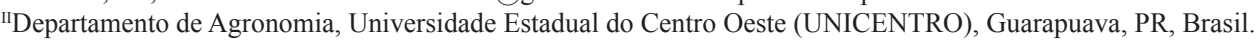

IIIDepartamento de Matemática, UNICENTRO, Guarapuava, PR, Brasil. 
interferência causada pelas plantas daninhas constitui um dos principais fatores que limitam o estabelecimento e persistência das forrageiras, principalmente como resposta da competição pelos recursos disponíveis no ambiente (AGOSTINETTO et al., 2008).

No manejo das plantas daninhas, fazse necessário o conhecimento dos períodos de interferência para que o controle, no momento adequado, permita à cultura expressar seu potencial produtivo (BIFFE et al., 2010). Os conceitos de período anterior à interferência $(\mathrm{PAI})$, período total de prevenção à interferência (PTPI), período crítico de prevenção à interferência (PCPI) e período posterior a interferência (PPI) foram propostos por PITELLI (1985). O PAI é conceituado como o período a partir da emergência ou do plantio, em que a cultura pode conviver com as plantas daninhas antes que a sua produtividade ou outras características sejam alteradas negativamente. O PTPI é o período total em que se deve tomar medidas de controle das plantas daninhas, que compreende o PAI e PCPI; ao final desse período temos o PPI, quando a presença de plantas daninhas não afeta negativamente a cultura. Como PCPI, entende-se o período em que se deve ter a ausência das plantas daninhas para que sua produtividade, qualidade da produção ou outras características não sejam alteradas negativamente, situando-se entre os limites superiores do PAI e do PTPI.

Dada a importância do trevo branco como forrageira e a inexistência de pesquisa sobre a interferência de plantas daninhas no seu estabelecimento, o objetivo deste trabalho foi determinar os períodos de interferência das plantas daninhas no estabelecimento do trevo branco.

\section{MATERIAL E METÓDOS}

O experimento foi realizado no campo experimental da UNICENTRO, no inverno de 2011, situada em latitude de $25^{\circ} 23^{\prime} 36^{\prime}$ 'S, longitude de $51^{\circ} 27^{\prime} 19^{\prime \prime} \mathrm{W}$ e altitude de $1.120 \mathrm{~m}$. O clima da região, segundo CAVIGLIONE et al. (2000), é o do tipo Cfb conforme a classificação de Köppen - Clima temperado propriamente dito; temperatura média no mês mais frio abaixo de $18{ }^{\circ} \mathrm{C}$ (mesotérmico), com verões frescos, temperatura média no mês mais quente abaixo de $22^{\circ} \mathrm{C}$ e sem estação seca definida. A precipitação média anual é de $1.944 \mathrm{~mm}$, temperaturas médias anuais mínima de $12,7^{\circ} \mathrm{C}$ e máxima de $23,5^{\circ} \mathrm{C}$. O solo da área experimental foi identificado como Latossolo bruno distroférrico típico, textura muito argilosa (EMBRAPA, 2006).

O preparo do solo foi convencional, realizado duas semanas antes da semeadura. A adubação foi realizada somente na linha de semeadura com de $120 \mathrm{~kg} \mathrm{ha}^{-1}$ de $\mathrm{P}_{2} \mathrm{O}_{5}, 60 \mathrm{~kg}$ ha-1 de $\mathrm{K}_{2} \mathrm{O}$ e $1,2 \mathrm{~kg} \mathrm{ha}^{-1}$ de B. No dia 14/03/2011, realizou-se a inoculação com Rhizobium trifolii e a semeadura em linhas espaçadas de $0,18 \mathrm{~m}$, profundidade de $0,05 \mathrm{~m}$ e densidade de $8 \mathrm{~kg} \mathrm{ha}^{-1}$. O período experimental foi de 119 dias após a emergência (DAE). As parcelas foram constituídas por 11 linhas de 1,20m de comprimento, com área útil para avaliação das sete linhas centrais, desprezando-se $20 \mathrm{~cm}$ de cada extremidade.

O delineamento utilizado foi em blocos inteiramente casualizados, com 36 tratamentos e 3 repetições. Os tratamentos consistiram em 18 períodos de controle e 18 de convivência da cultura com as plantas daninhas. No primeiro grupo de tratamentos, a cultura conviveu com as plantas daninhas por 18 períodos a partir da emergência desta: 0, 0-7, 0-14,0-21, 0-28, 0-35, 0-42, 0-49, 0-56, $0-63,0-70,0-77,0-84,0-91,0-98,0-105,0-112$, 0-119 dias em convivência com o mato (período de convivência com o mato), a partir dos quais a cultura foi mantida livre da competição das plantas daninhas, por meio de capinas e arranque manual, realizados sistematicamente 2 vezes por semana por 4 pessoas até o momento da colheita. No segundo grupo, a cultura permaneceu livre da competição com as plantas daninhas, por meio de capinas, por 18 períodos, a partir da emergência: 0, 0-7, 0-14,0-21, 0-28, 0-35, $0-42,0-49,0-56,0-63,0-70,0-77,0-84,0-91,0-98$, 0-105, 0-112, 0-119 dias mantidas no limpo (período de controle do mato), por meio de capinas e arranque manual, realizados sistematicamente, duas vezes por semana, por quatro pessoas. Após cada uma dessas épocas, as plantas daninhas que emergiram foram deixadas crescer livremente.

Para comunidade de plantas daninhas, foi realizado o levantamento fitossociológico, sendo avaliada em cada período de convivência com o mato e aos 119 dias para os períodos de controle do mato, efetuando-se quatro amostragens dentro da área útil da parcela, utilizando um quadro com dimensões de $0,5 \times 0,5 \mathrm{~m}$. As partes aéreas das plantas daninhas encontradas nas amostras foram coletadas e, conforme a metodologia proposta por MUELLERDOMBOIS \& ELLEMBERG (1974), foram determinados o número de indivíduos, o acúmulo de massa de matéria seca e a frequência de ocorrência de cada espécie, que, por sua vez, foram utilizados no cálculo do índice de valor de importância (IVI): $\mathrm{IVI}=\mathrm{DR}+\mathrm{FR}+\mathrm{DoR}$.

Neste, IVI representa o índice de valor de importância; DR - densidade relativa de cada espécie, que é a razão entre o número de plantas 
de uma espécie e o total de plantas amostradas, expressa em porcentagem; FR - frequência relativa, ou seja, frequência com que a espécie ocorreu nas amostragens, expressa em porcentagem; e o DoR dominância relativa, razão entre a massa de matéria seca da espécie e o total de massa de matéria seca amostrado, expressa em porcentagem. Obtendo-se o valor do IVI, procedeu-se o cálculo da importância relativa (IR). A IR é determinada por meio da razão entre o IVI de cada espécie e o somatório dos IVIs de todas as espécies, expressa em porcentagem: $\mathrm{IR}=\mathrm{IVI} / \mathrm{IVIs}$.

A matéria seca da parte aérea das plantas daninhas e do trevo branco foi obtida pela secagem em estufa com circulação de ar forçado a $65^{\circ} \mathrm{C}$, até atingir massa constante. Os dados de produção de matéria seca de trevo branco foram então ajustados ao modelo de regressão não linear sigmoidal de Boltzmann, descrito por: $\mathrm{Y}=\mathrm{A} 2+\{(\mathrm{A} 1-\mathrm{A} 2) /[1+\exp ((\mathrm{X}-\mathrm{X} 0) / \mathrm{dx})]\}$.

Nesse modelo, $\mathrm{Y}$ é a produção em $\mathrm{kg}$ $\mathrm{ha}^{-1}$; A1, a produção em $\mathrm{kg} \mathrm{ha}^{-1}$ obtida nas parcelas mantidas na ausência de plantas daninhas durante todo o ciclo; A2, a produção em $\mathrm{kg} \mathrm{ha}^{-1}$ obtida nas parcelas mantidas na presença de plantas daninhas durante todo o ciclo; X são os dias após a emergência (DAP); $\mathrm{X} 0$, o limite superior do período de convivência ou controle que corresponde ao valor intermediário entre o estande máximo e o mínimo; e Dx é tg $\alpha$ no ponto X0 (ponto de inflexão da curva).

A partir das equações de regressão, foram determinados os períodos de interferência das plantas daninhas, adotando-se um nível de tolerância de redução da produtividade do trevo branco de $5 \%$.

\section{RESULTADOS E DISCUSSÃO}

Nas avaliações da comunidade infestante na cultura do trevo branco, foram identificadas as espécies que estavam presentes no campo experimental, as quais são apresentadas na tabela 1 . Houve a predominância das plantas daninhas magnoliopsidas, $78,5 \%$, enquanto as liliopsidas representavam $21,5 \%$ da população.

Foram identificadas 14 espécies de plantas daninhas, pertencentes a sete famílias botânicas (Tabela 1). A família mais frequente foi Asteraceae, na qual foram encontradas as espécies Sonchus oleraceus L., Taraxacum officinale F.H. Wigg., Soliva pterosperma (Juss.) Less., Hypochoeris brasiliensis (Less.) Griseb. e Ambrosia elatior L. (Tabela 1). INOUE et al. (2012), realizando um levantamento fitossociológico em pastagens, também encontrou a família Asteraceae como a mais frequente. As principais Poaceae foram Lolium multiflorum Lam. e Sorghum bicolor (L.) Moench X S. sudanense (Piper) Stapf.

$\mathrm{O}$ índice de importância relativa (IR) de cada planta daninha em cada período de convivência é apresentado na figura 1 para os períodos de convivência com o mato e na figura 2 para os períodos de controle do mato. Nos períodos de convivência com o mato, Sorghum bicolor (L.) Moench X S. sudanense (Piper) Stapf. apresentou os maiores valores de IR nos períodos iniciais de convívio (Figura 1), resultado atribuído ao fato de o banco de sementes na área conter uma grande quantidade dessa planta. Aos 65 dias após a emergência, houve geada, eliminando Sorghum bicolor (L.) Moench X

Tabela 1 - Comunidade infestante encontrada nos períodos de controle do mato e períodos de convívio com o mato do trevo.

\begin{tabular}{|c|c|c|c|}
\hline Nome científico & Nome comum & Família & Código* \\
\hline Sonchus oleraceus L. & Serralha & Asteraceae & SONOL \\
\hline Taraxacum officinale F.H. Wigg. & Dente-de-leão & Asteraceae & TAROF \\
\hline Raphanus raphanistrum L. & Nabiça & Brassicaceae & RAPRA \\
\hline Plantago tomentosa Lam. & Tanchagem & Plantaginaceae & PLATO \\
\hline Verbascum virgatum Stockes & Barbasco & Scrophulariaceae & VESVI \\
\hline Cenchrus echinatus L. & Capim-carrapicho & Poaceae & CCHEC \\
\hline Sida rhombifolia L. & Guanxuma & Malvaceae & SIDRH \\
\hline Soliva pterosperma (Juss.) Less. & Roseta & Asteraceae & SOVPT \\
\hline Hypochoeris brasiliensis (Less.) Griseb. & Almeirão-do-campo & Asteraceae & HRYBR \\
\hline Lolium multiflorum Lam. & Azevém & Poaceae & LOLMU \\
\hline Bidens pilosa L. & Picão-preto & Asteraceae & BIDPI \\
\hline Ambrosia elatior L. & Losna-do-campo & Asteraceae & AMBEL \\
\hline Vicia sativa $\mathrm{L}$. & Ervilhaca & Fabaceae & - \\
\hline Sorghum bicolor (L.) Moench X S. sudanense (Piper) Stapf. & Sorgo forrageiro & Poaceae & SORSS \\
\hline
\end{tabular}

*Código internacional, segundo International Weed Society. 


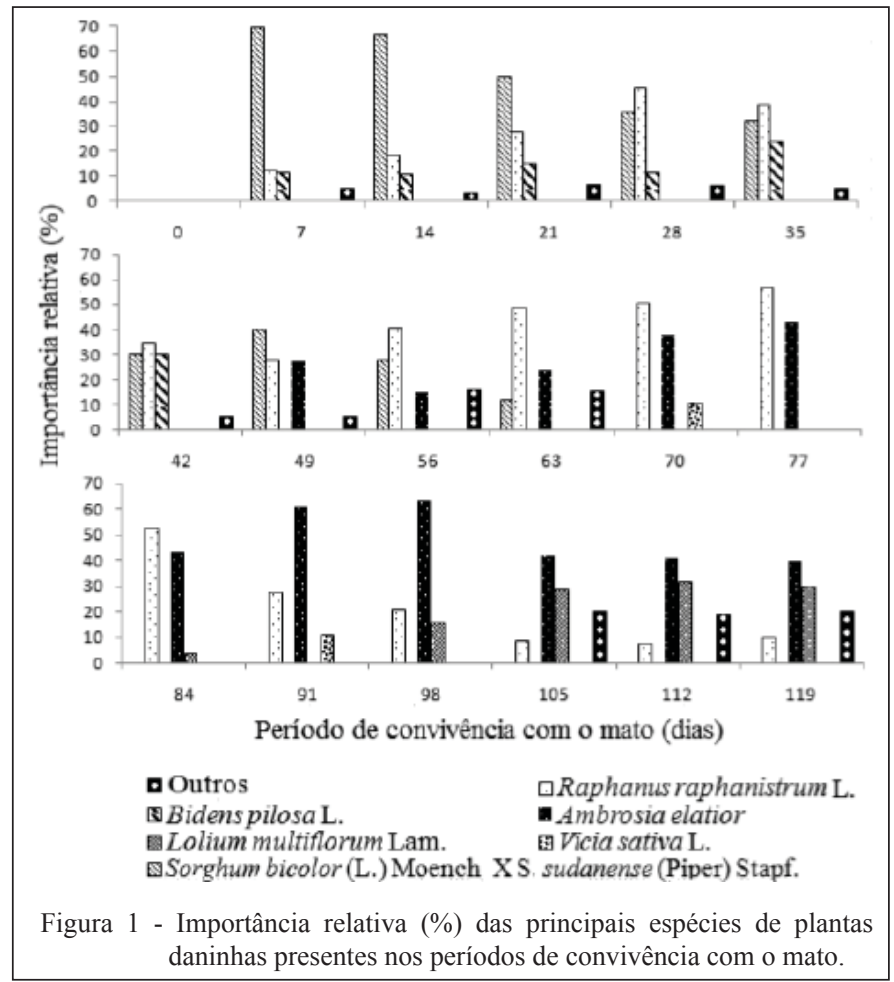

S. sudanense (Piper) Stapf. (Figuras 1 e 2). A partir de então, Raphanus raphanistrum L. começou a ter o maior IR, chegando próximo ao final dos períodos de convivência com o mato, Ambrosia elatior L. foi a responsável pela maior interferência. Ambrosia elatior L., Lolium multiflorum Lam. e Sonchus

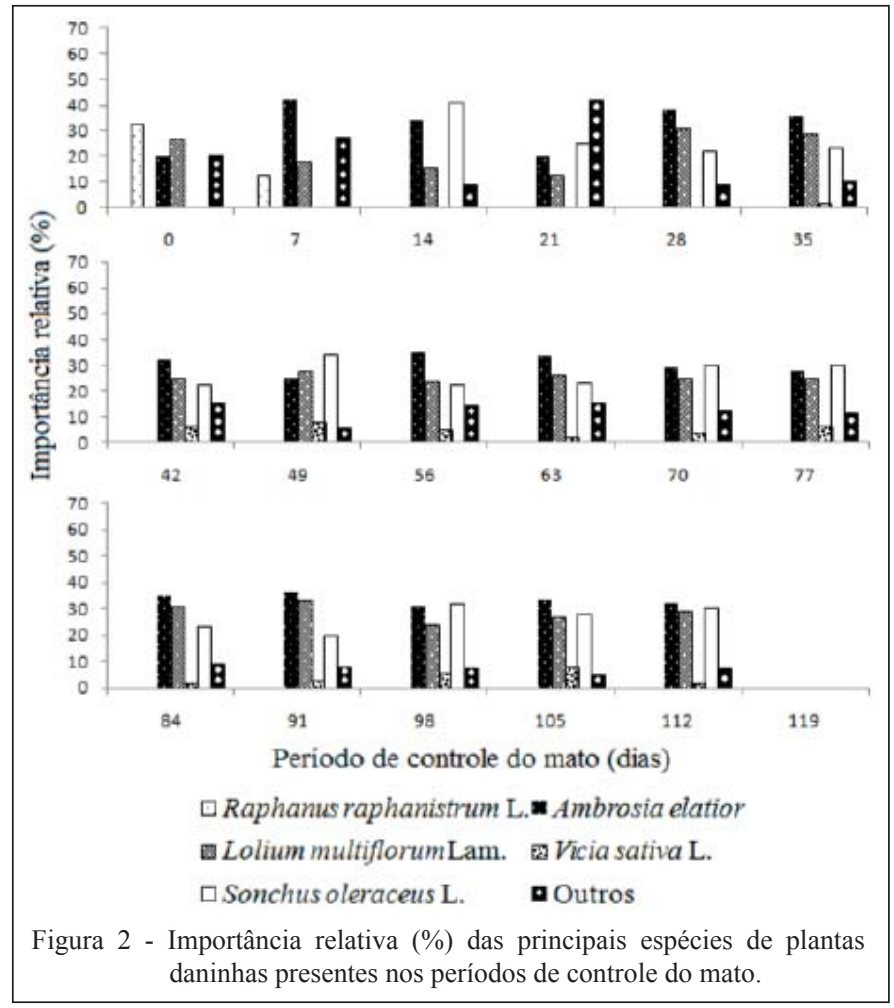

Ciência Rural, v.43, n.12, dez, 2013. 
oleraceus L. foram as plantas daninhas com maiores IR durante todo o período de controle do mato, sendo consideradas, portanto, as principais causadoras da interferência no trevo branco.

A partir das curvas de produção de matéria seca do trevo branco (Figura 3), ajustadas ao modelo de regressão não linear, em função dos períodos de controle e convivência das plantas daninhas com a cultura, foi possível determinar que o PAI foi de 20 dias após a emergência (DAE), sendo que seu final reflete o momento em que inicia a competição interespecífica pelos recursos. Assim, determinando que até 20DAE não se faz necessário nenhuma medida de controle da comunidade infestante. Quanto ao PTPI, este se estendeu até 82DAE. Seu final PPI reflete o momento em que o controle da comunidade de plantas daninhas não produzirá qualquer benefício à produção da cultura, pois as plantas daninhas que emergem após o PTPI não atingem crescimento suficiente para realizarem competição interespecífica com a cultura, não sendo recomendado o controle após 82DAE. PCPI é determinado pelos finais do PAI e do PTPI, iniciando aos 20DAE e se estende até os 82DAE, ou seja, é necessário que medidas de controle sejam iniciadas aos 20DAE, prolongandose por mais 62 dias para que a cultura fique mantida livre da competição com plantas daninhas e não ocorra redução na produção.

A emergência do trevo, segundo DEN HOLLANDER et al. (2007a), ocorre cerca de 20 dias após a semeadura e, devido ao pequeno tamanho de suas sementes, ele dá origem a plântulas pequenas, apresentando um desenvolvimento inicial lento após a emergência (LUSTOSA et al., 2011). Esse fato, aliado ao revolvimento do solo no sistema de preparo convencional, ocasiona a expressão do banco de sementes, logo após a semeadura, quando ocorre um grande fluxo de emergência de plantas daninhas, as quais exercem forte competição intraespecífica (MESCHEDE et al., 2004). Esses motivos podem explicar o PAI relativamente curto encontrado neste trabalho.

Em estudo sobre a habilidade competitiva de diferentes trevos, DEN HOLL ANDER et al. (2007b) verifica que o trevo branco tem baixa habilidade competitiva antes da cobertura completa do solo, mas, após a cobertura do solo, o trevo branco apresenta elevada habilidade competitiva, sendo que a cobertura do solo, segundo o seu estudo, ocorre por volta de $80 \mathrm{DAE}$, apresentando $100 \%$ de interceptação luminosa. Esses resultados são semelhantes aos encontrados na figura 3, em que o PPI inicia aos 82 dias. Assim a habilidade competitiva do trevo branco

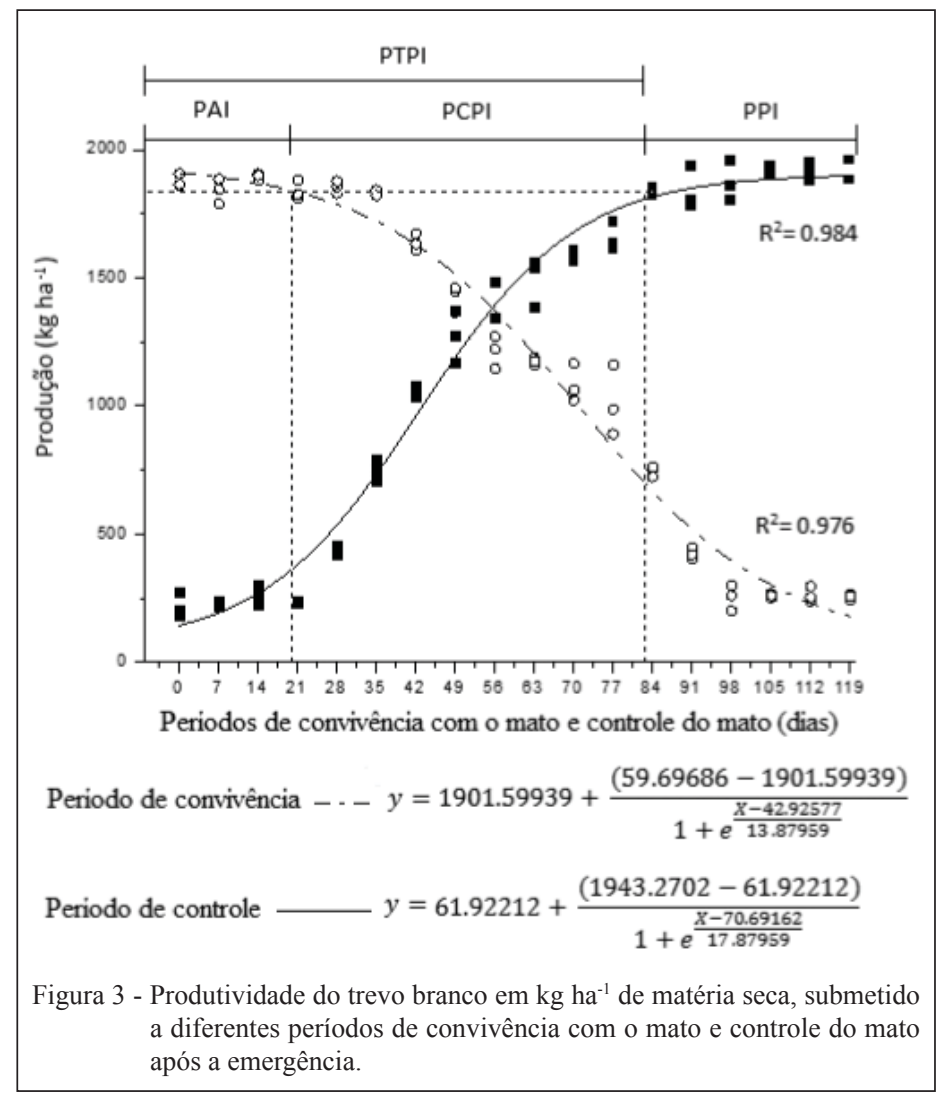

Ciência Rural, v.43, n.12, dez, 2013. 
após a cobertura do solo não permitiu decréscimos significativos na produção.

Analisando os parâmetros da equação dos períodos de convivência com o mato (Figura 3 ), em que (A1-A2/A2) x 100 expressa a perda de produtividade, esta foi de $96 \%$, evidenciando assim a importância do controle das plantas daninhas no estabelecimento do trevo branco. A redução (dx) foi de $13,9 \mathrm{~kg} \mathrm{ha}^{-1}$ a cada dia de convívio com o mato e uma redução de $50 \%$ na produtividade (x0) próxima dos de 43DAE. Assim, o controle das plantas daninhas foi essencial para o ganho de produtividade dessa cultura. Esse fato pode ser observado quando se analisam os parâmetros da equação de regressão dos períodos de controle do mato (Figura 3), nos quais a velocidade em que ocorre ganho de produtividade $(\mathrm{dx})$ foi de $17,8 \mathrm{~kg} \mathrm{ha}^{-1}$ dia, atingindo $50 \%$ da produtividade final $(\mathrm{x} 0)$ por volta de 71 dias.

No período de estabelecimento, quando o controle de plantas daninhas torna-se necessário, são encontradas dificuldades, devido à inexistência de produtos comerciais registrados para o manejo químico da cultura. Portanto, observa-se a importância da indicação de uso de herbicidas seletivos ao trevo branco.

\section{CONCLUSÃO}

O controle de plantas daninhas no estabelecimento do trevo branco deve ser iniciado aos 20 dias após a emergência (PAI) prolongando-se por mais 62 dias (PCPI).

\section{REFERÊNCIAS}

AGOSTINETTO, D. et al. Período crítico de competição de plantas daninhas com a cultura do trigo. Planta Daninha, v.26, n.2, p.271-278, 2008. Disponível em: <http://www.scielo.br/ scielo.php?script $=$ sci_arttext\&pid=S010083582008000200003\&1 ng=en\&nrm=iso $>$. Acesso em: 06 ago. 2012. doi: 10.1590/S010083582008000200003 .

ANUALPEC. Anuário da pecuária brasileira. 19.ed. São Paulo: Instituto FNP, 2011. 360p.

ASSMANN, T.S. et al. Fixação biológica de nitrogênio por plantas de trevo (Trifolium spp) em sistema de integração lavoura-pecuária no Sul do Brasil. Revista Brasileira Zootecnia, v.36, n.5, p.1435-1442, 2007. Disponível em: $<$ http://www.scielo.br/scielo.php?script=sci_ar ttext\&pid=S151635982007000600029\&lng=en\&nrm=iso $>$. Acesso em: 06 ago. 2012. doi: 10.1590/S1516-35982007000600029.

BARCELLOS, A.O. et al. Sustentabilidade da produção animal baseada em pastagens consorciadas e no emprego de leguminosas exclusivas, na forma de banco de proteína, nos trópicos brasileiros. Revista Brasileira de Zootecnia, v.37, p.51-67, 2008. Disponível em: <http://www.scielo.br/scielo. php?script $=$ sci arttext\&pid $=$ S151635982008001300008\&lng= en\&nrm=iso $>$. Acesso em: 6 ago. 2012. doi: 10.1590/S151635982008001300008 .

BIFFE, D.F. et al. Período de interferência de plantas daninhas em mandioca (manihot esculenta) no noroeste do Paraná. Planta Daninha, v.28, n.3, p.471-478, 2010. Disponível em: <http:// www.scielo.br/scielo.php?script $=$ sci arttext\&pid $=$ S0 1008358200 $8000200004 \& \operatorname{lng}=\mathrm{en} \& \mathrm{nrm}=\mathrm{iso}>$. Acesso em: 6 ago. 2012. doi: 10.1590/S0100-83582008000200004.

CAVIGLIONE, J.H. et al. Cartas climáticas do Paraná. Londrina: IAPAR, 2000. $1 \mathrm{CD}$.

DEN HOLLANDER, N.G. et al. Clover as a cover crop for weed suppression in an intercropping design I. Characteristics of several clover species. European Journal of Agronomy, v.26, n.1, p.92-103, 2007a. Disponível em: <http://www. sciencedirect.com/science/article/pii/S1161030106001109>. Acesso em: 6 ago. 2012. doi: 10.1016/j.eja.2006.08.011.

DEN HOLLANDER, N.G. et al. Clover as a cover crop for weed suppression in an intercropping design II. Competitive ablity of several clover species. European Journal of Agronomy, v.26, n.1, p.104-112, 2007b. Disponível em: <http:/www.sciencedirect. com/science/article/pii/S1161030106001080>. Acesso em: 6 ago. 2012. doi: 10.1016/j.eja.2006.08.005.

EMBRAPA. Centro Nacional de Pesquisa de Solos. Sistema brasileiro de classificação de solos. 2.ed. Brasília: Embrapa, 2006. 306p.

INOUE, M.H. et al. Levantamento fitossociológico em pastagens. Planta Daninha, v.30, n.1, p.55-63, 2012. Disponível em: $<$ http://www.scielo.br/scielo.php?script $=$ sci_arttext\&pid=S0100$83582004000300003 \& \operatorname{lng}=\mathrm{en} \& \mathrm{nrm}=\mathrm{iso}>$. Acesso em: 6 ago. 2012. doi: 10.1590/S0100-83582004000300003.

LUSTOSA, S.B.C. et al. Experiências de integração lavourapecuária na região central do Paraná. Synergismus scyentifica, v.6, n.2, p.48-57, 2011. Disponível em: <http://revistas.utfpr. edu.br/pb/index.php/SysScy/article/view/1430>. Acesso em: 6 ago. 2012.

MESCHEDE, D.K. et al. Período anterior à interferência em soja: estudo de caso com baixa densidade de estande e testemunhas duplas. Planta Daninha, v.22, n.2, p.239246, 2004. Disponível em: <http://www.scielo.br/scielo. php?script $=$ sci_arttext\&pid $=$ S0100-83582004000200010\&lng $=$ en $\&$ nrm $=$ iso $>$. Acesso em: 6 ago. 2012. doi: 10.1590/S010083582004000200010 .

MUELLER-DOMBOIS, D.; ELLENBERG, G.H. Aims and methods of vegetation ecology. New York: Willey \& Sons: 1974. 547p.

PITELLI, R.A. Interferências de plantas daninhas em culturas agrícolas. Informe Agropecuário, v.11, n.129, p.16-27, 1985 . 